\title{
Collection of Metaphors for Human-Robot Interaction
}

\section{Patrícia Alves-Oliveira ${ }^{1}$, Maria Luce Lupetti ${ }^{2}$, Michal Luria ${ }^{3}$, Diana Löffler ${ }^{4}$, Mafalda Gamboa ${ }^{5}$, Lea Albaugh ${ }^{3}$, Waki Kamino ${ }^{6}$,}

Anastasia K. Ostrowski ${ }^{7}$, David Puljiz ${ }^{8}$, Pedro Reynolds-Cuéllar ${ }^{7}$, Marcus Scheunemann ${ }^{9}$, Michael Suguitan ${ }^{10}$, Dan Lockton ${ }^{11}$

${ }^{1}$ University of Washington, ${ }^{2}$ Delft University of Technology, ${ }^{3}$ Carnegie Mellon University, ${ }^{4}$ University of Siegen, ${ }^{5}$ Chalmers University of Technology, ${ }^{6}$ Indiana University, ${ }^{7} \mathrm{MIT}$ Media Lab, ${ }^{8} \mathrm{Karlsruhe}$ Institute of Technology, ${ }^{9}$ University of Hertfordshire, ${ }^{10}$ Cornell University, ${ }^{11}$ Eindhoven University of Technology Contact author: patri@uw.edu

\section{ABSTRACT}

The word "robot" frequently conjures unrealistic expectations of utilitarian perfection: tireless, efficient, and flawless agents. However, real-world robots are far from perfect- they fail and make mistakes. Thus, roboticists should consider altering their current assumptions and cultivating new perspectives that account for a more complete range of robot roles, behaviors, and interactions. To encourage this, we explore the use of metaphors for generating novel ideas and reframing existing problems, eliciting new perspectives of human-robot interaction. Our work makes two contributions. We (1) surface current assumptions that accompany the term "robots," and (2) present a collection of alternative perspectives of interaction with robots through metaphors. By identifying assumptions, we provide a comprehensible list of aspects to reconsider regarding robots' physicality, roles, and behaviors. Through metaphors, we propose new ways of examining how we can use, relate to, and co-exist with the robots that will share our future.
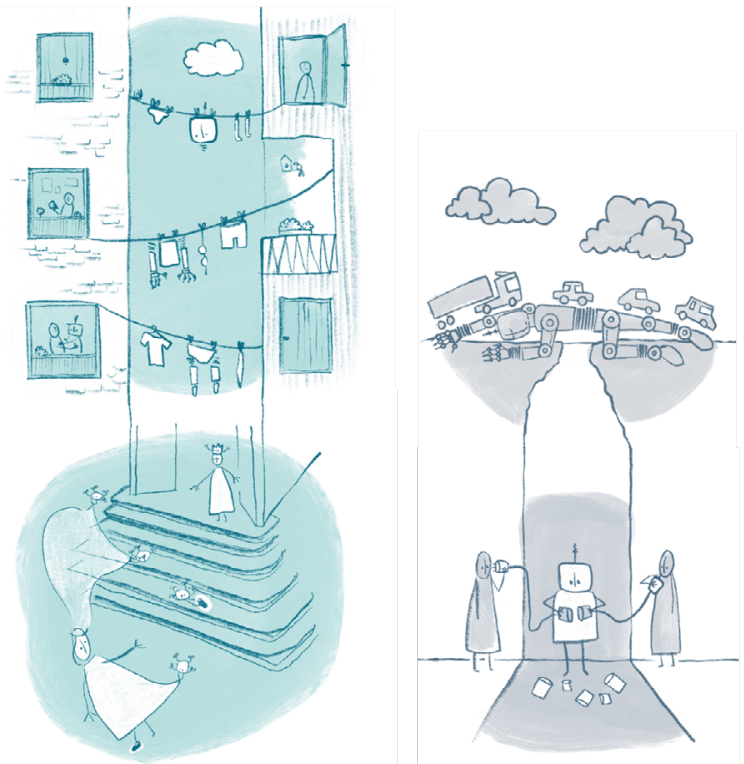

Fig 1. Metaphors of human-robot interactions: clothing,

bridge, parrot, swetness, tumor, fragility, and paint.

\section{Authors Keywords}

human-robot interaction; robot assumptions; metaphors; fixation; design research.

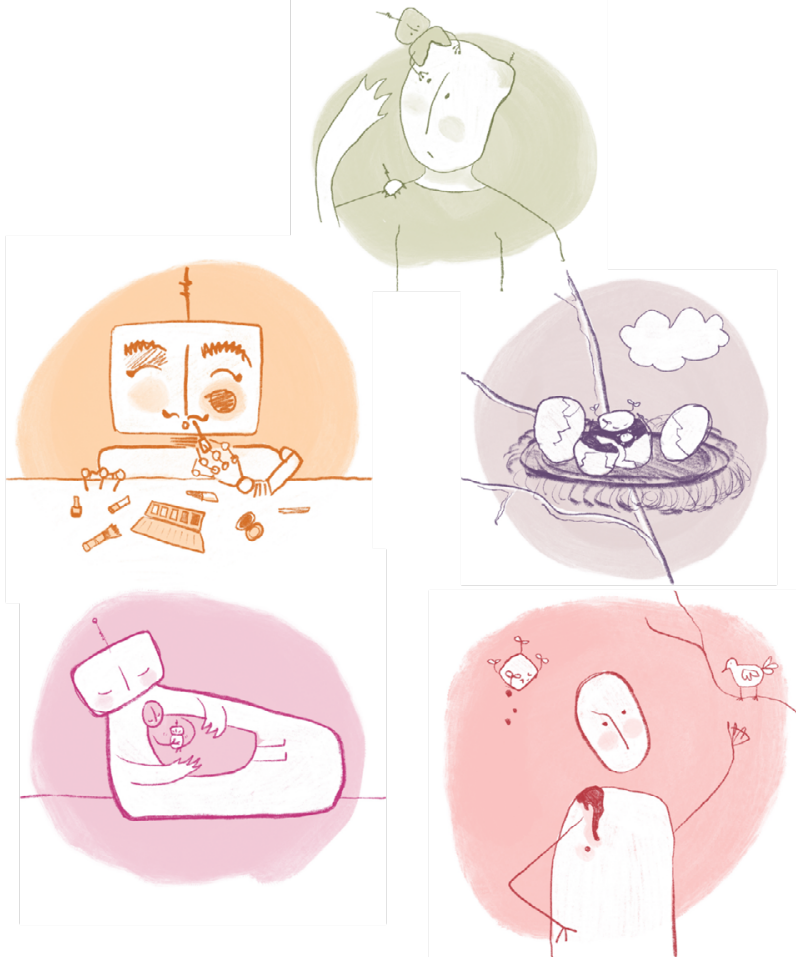

CCS Concepts

- Human-centered computing Interaction Design Interaction design theory, concepts and paradigms 


\section{INTRODUCTION}

Human-robot interaction (HRI) offers fertile ground for interaction design research. Defined as a field dedicated to 'understanding, designing, and evaluating robotic systems for use by or with humans' [24], HRI is increasingly engaged in investigating interactions not only in computational terms, but in terms of the social, cultural, and ethical implications of what a robot is, the purpose it serves, and its intended behavior [4]. Conducting robotic design research poses a unique challenge for human-computer interaction and other design fields as it is one of the few novel interfaces with a long history of pre-existing assumptions strongly linked to the word "robot." Etymologically, "robot" denotes slavery or forced labor, notions that persist to modern times [51].

Over the last decade, the field of HRI has witnessed the growing use of design methods and approaches that stem from human-centered design considerations (see the dedicated workshop [19], to HRI evaluation methods like the USUS [62]), to speculative and critical design explorations (e.g., $[4,12])$. These methods help researchers address robotic projects more holistically, by understanding the needs of potential users and implications of specific contexts [6]. Interaction design explorations, then, not only contribute to the development of form, function, and desired effects of robots, but they also invite researchers to reflect on the philosophical, ethical, and political implications that specific robot designs and projects might entail [6].

As designers engaged in HRI work, we posit that the field suffers from some fixed thinking about what a robot is and what functions it should serve. Dominant are the ideas of robots as lifelike [7] and fully autonomous agents [8]; notions of robot utility [50], efficiency [57] and predictability [20]; and the overall misconception that robot behaviors must always be positive. Fixation is described as an 'effect in which an individual might unconsciously focus on certain aspects of an object or a task, whilst leaving others aside' [59]; in the specific case of design practices, fixated thinking has been

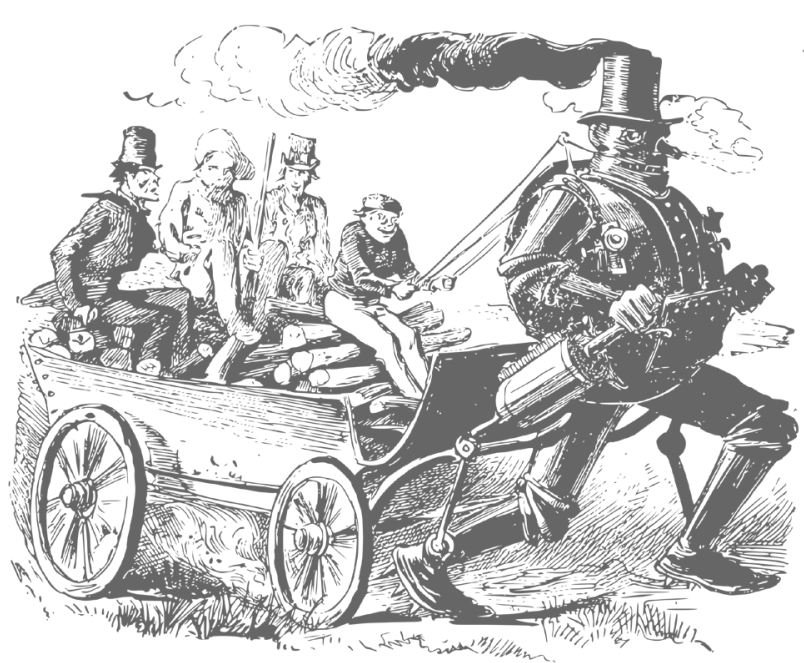

Fig 2. Cover of The Huge Hunter, or The Steam Man of the Prairies by Edward S. Ellis (1882 edition), Unknown author (public domain).

demonstrated when lead designers blindly adhere to a limited set of ideas in the design process [30]. Similarly, fixation in HRI stands in the way of alternative approaches to robot design [4], obscuring the values that could meaningfully inspire and guide our understanding of future human-robot relationships.

In the design field, the problem of fixation is not new, as testified by a vast literature dedicated to understanding the topic and proposing ways to tackle it $[16,44,54,61$, 64]. Among these, the use of metaphors is increasingly acknowledged as a powerful strategy to deal with fixation since they let us break assumptions that stem creative thinking $[10,11,13,14,32,36,46,55]$. Metaphors are a way to think and talk about one kind of thing in terms of another [35]. For example, the metaphor 'a robot is a servant' frames a robot as a submissive entity that performs duties for its owner. As such, metaphors affect how we think and approach problems and products and are not limited to being mere figures of speech. They can inform design decisions [29] and highlight different aspects of a complex concept like a robot, from details of interfaces (e.g., 'a sad robot is blue' [39]) to wider societal images of the technology (e.g., 'a robot is a human' [5]).

Current dominant assumptions in HRI either conceptualize the robot as a mechanical tool to be operated or as a 'being,' taking as reference the interaction with other humans or pets [38]. While undoubtedly having advantages, these approaches nonetheless hinder meaningful explorations of what might be non-human/pet-centric ways of interacting and relating with robots. To address this limitation and challenge current assumptions we hold about robots, we believe design research in HRI should explore metaphors as a tool for envisioning and developing artificial social agents that exceed in form and utility the dominant anthropomorphic or zoomorphic paradigms.

This paper builds on emerging HRI practices and experiences from the design field to illustrate and discuss metaphors as an agent of change in robotic design. We examine the 'otherness' of robots through alternative proposals of design interactions between humans and robots [25] rather than by mimicking existing lifeforms. Specifically, we use and extend the "New Metaphors" method [36]. Through this, we conceptualize new metaphors, new ways of imagining modes of interactions and forms of robots that transcend existing dominant views. We believe this approach can enrich the spectrum of possible robot imaginaries and help HRI design researchers develop more diverse and nuanced visions of future human-robot coexistence. Another contribution of this work is surfacing underlying assumptions that exist about robots, a necessary step toward innovative future designs.

\section{BACKGROUND: THE ROLE OF METAPHORS IN DESIGN}

As classically defined, metaphors are described as "figures of speech in which a word or phrase literally denoting one kind of object or idea is used in place of another to suggest a likeness or analogy between them", e.g., "drowning in money" [43]. But, as argued 
by [52] and echoed by [10], "a metaphor is more than a grammatical device: it is a cognitive structure that plays a significant role in the transference of concepts between two complex conceptual systems." As such, these figures of speech help us understand and make sense of everyday concepts like time, problems, and emotions [28].

Metaphors pervade everyday life, not just through language, but also in the way we think and act [35]. As such, they play a crucial role in understanding and practicing the design discipline. Indeed, the act of designing is often presented and discussed through various metaphors [28], like: a search; a process of exploration; a journey or bricolage. And, as argued by [27], the very language of design is highly metaphorical: narrowing down on a concept; bouncing around ideas; breaking the problem down; finding a route to a solution; encouraging wild ideas, and more.

Metaphors also have several practical implications in design. First, they are largely used to enhance products' aesthetics and evocativeness [9, 13, 27]. In this case, defined as a product metaphor [26], the physical properties of a product intentionally reference another entity for expressive purposes (see the Mary Biscuit box by Alessi shaped like a biscuit). Through metaphors, the product is imbued with meanings and values [13]. Relatedly, another common use of metaphors in design is to facilitate product understanding $[27,32]$, which is particularly important when introducing novel products and technologies. A popular example of this use is the desktop metaphor, adopted to facilitate users' interaction with the first software interfaces [27, 32].

Metaphors, then, are heavily used in the design process itself. They enable team work [27] by allowing design teams to develop a shared vision and understanding of problems and solutions. They facilitate the framing of problems and situations [10,11, 17, 27, 28] since engaging in a process of comparison fosters the development of new inferences and helps designers construct problems in unique, insightful ways [28].
Metaphors are also powerful tools that designers can use to break assumptions and stimulate creativity $[10,11,13$, $14,32,36,46,55]$ : they enable novel associations with the design problem and exploration of unfamiliar design alternatives $[10,11,14]$. In this work, we explored the latter use of metaphors in design, i.e., the capacity for metaphors to bring new perspectives to product design [32]. Using metaphors in this way can help us change how we conceptualize and develop robot designs and relationships between humans and robots.

\section{METAPHORS CHALLENGING HUMAN-ROBOT \\ INTERACTION ASSUMPTIONS}

Many problems are associated with fixation on certain assumptions in HRI. First, envisioning the design and development of robots only in utilitarian terms, i.e., making robots primarily into servants and encoding particular norms around power structures, contributed to dull and repetitive interactions with robots [22]. This is shown in long-term studies where user engagement tend to decline with time of interaction, highlighting the challenge of maintaining high engagement over prolonged interaction times [1], [31].

Second, robots are assumed to be entities with absolute knowledge and capabilities. While this assumption might arise from pop sci-fi culture, real robot's potentials and skills remain far more limited than what assumptions dictate. For example, a study showed that in emergency evacuation scenarios, people tend to trust robots that point to an unknown and obscure path rather than follow clearly marked exit signs. Our misplaced trust in robots is likely part of the unchallenged assumptions we hold about their intelligence [47]. Also, many robots fail to meet our hardware assumptions of ongoing and uninterrupted functioning. Their parts break, and replacement costs can be higher than expected. As a consequence, many robotics companies are failing because market price does not justify promised benefits [63].

Third, robots make many mistakes, perhaps more than humans. For a lay user, this may be an unexpected and disappointing reality. An entire research direction in
HRI focuses on how robots recover from their mistakes $[34,45]$. An important - yet largely neglected - aspect to consider while designing robots is the surprisingly common occurrence of robot error, which is critical to being able to move away from assumptions of perfection and towards core benefits that robots can provide.

Given these problems, the HRI field has begun to adopt speculative and critical design approaches that explore the use of metaphors, more or less explicitly, to challenge robot assumptions. Concepts like 'neediness' [21], 'domestication' [4], 'destruction' [42], and 'citizenship' [41] have been particularly used to broaden the HRI discourse beyond utilitarian values and mimetic approaches. In 'Technological Dream Series: No. 1: Robots, 2007' [21], Dunne \& Raby break down robot ideals of autonomy and efficiency through concepts like neediness which, by suggesting human-robot co-dependency, represents an unconventional strategy to mantain a human sense of control over the robot.

The concept of domestication [4] is explored by Auger to move a critique to a diffused maladaptation of robots to everyday life. Through this concept, the author suggests to look at analogous processes that happen in the animal kingdom, where natural beings become domestic things, as a way to focus on possible strategies of adaptation which, in return, would allow robots to meet their promised potential.

Through the concept of destruction, Luria et al. [42] opened a dialogue about the robot lifecycle and values beyond utilitarian role. By being inherently connected to the process of creation, the concept of destruction lead us to consider the possible symbolic meaning of robot materiality. A robot that breaks into parts can symbolize the longing for the other half in long-distance relationships, but remain functional even without it. In this case, destruction of the robot's physical parts symbolizes the distance between two people but can also serve as a reminder of their strong relationship.

Finally, by using the concept of citizenship, Lupetti et al. [41] described the future of robots' sociality and 


\section{IDENTIFYING NEW ROBOT METAPHORS: A COLLABORATIVE ONLINE EXPLORATION}
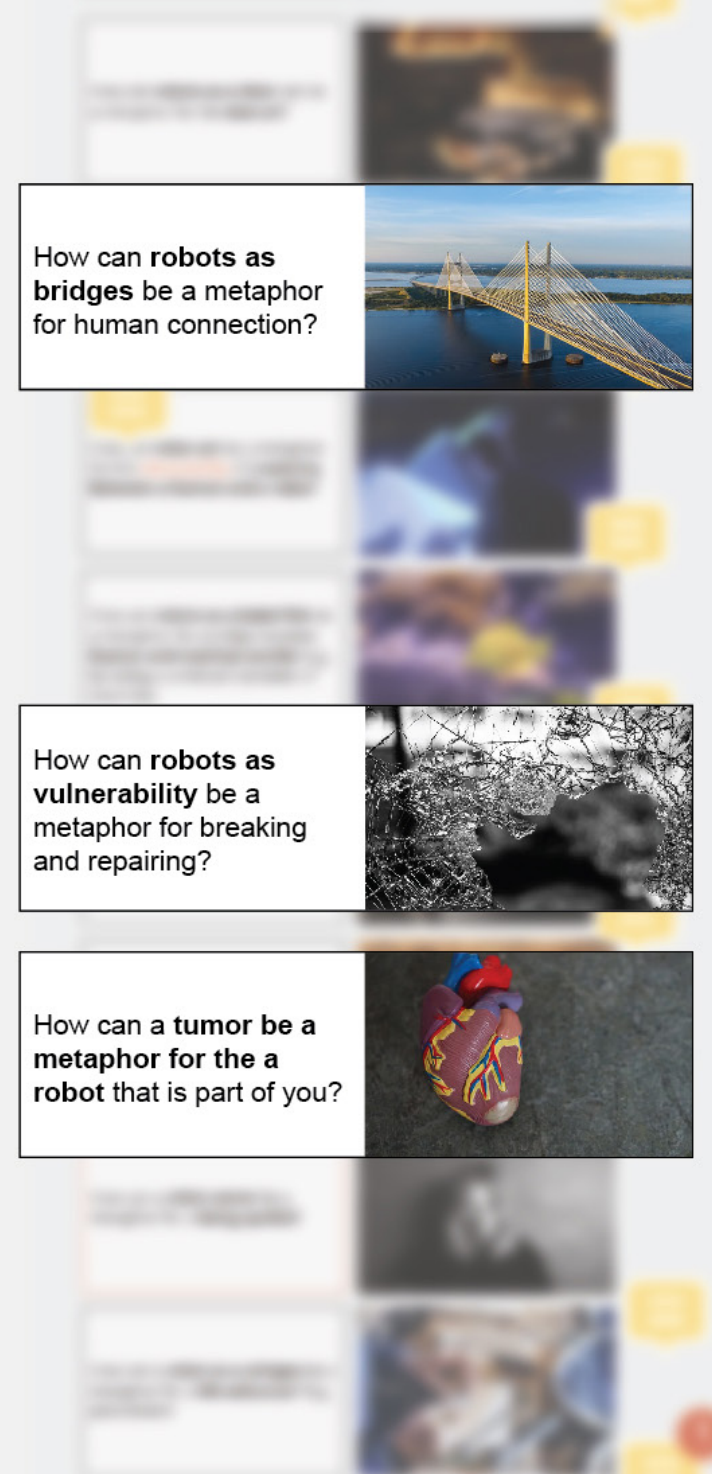
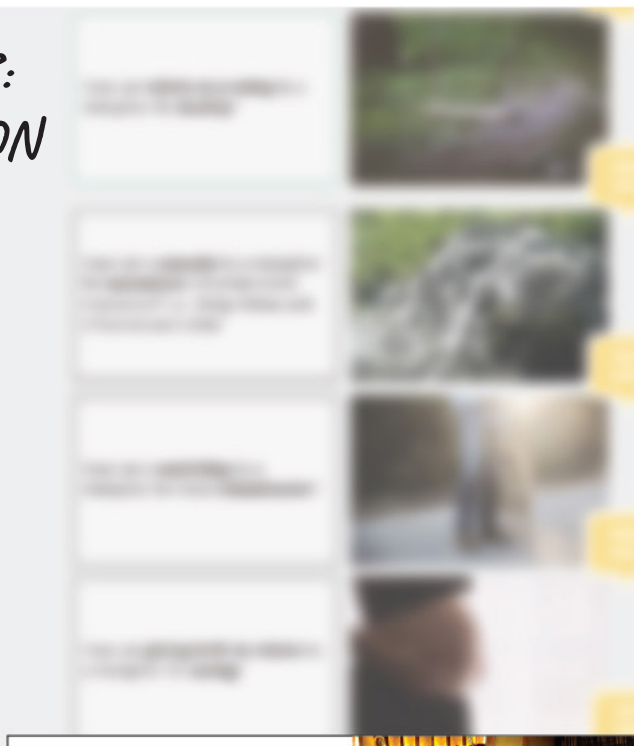

How can robots as a choir can be a metachoir can be a meta-
phor for the new art?

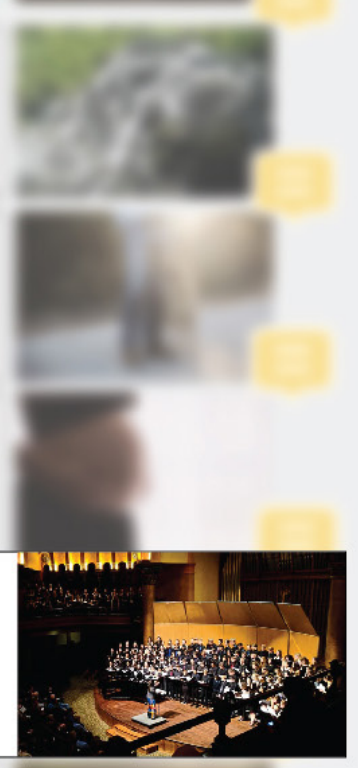

phiction a

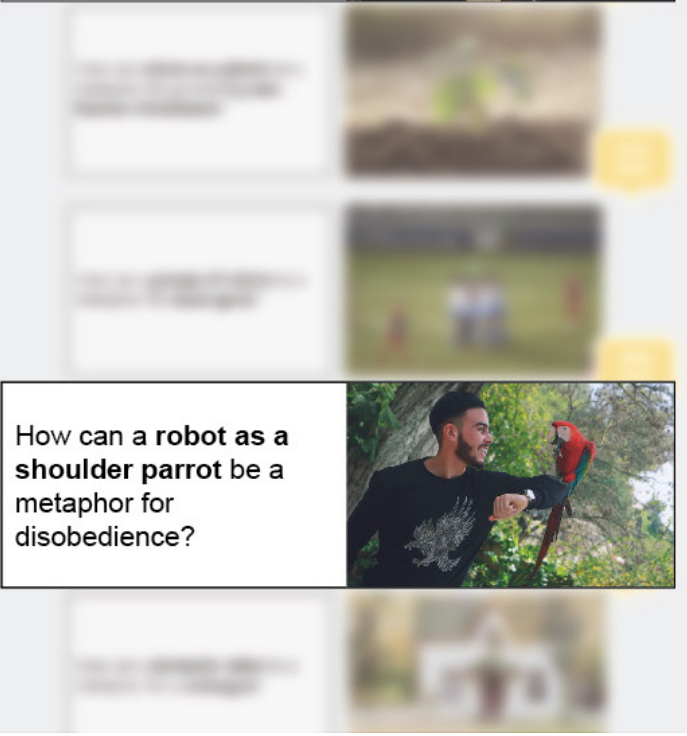

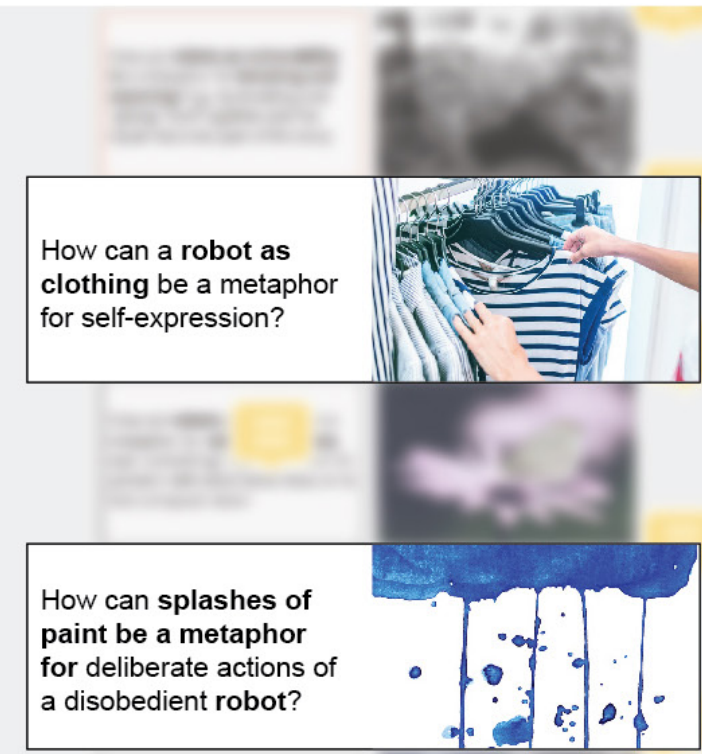

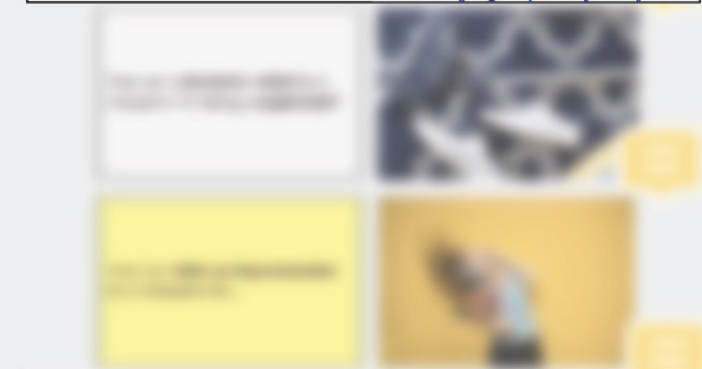

How can robot as sweetness be a

metaphor for addiction

and pleasure? I.e.,

Guilty pleasure

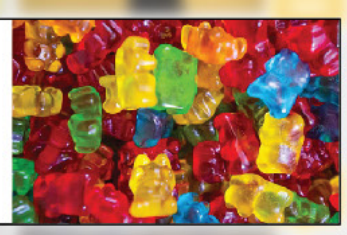

Fig 3. Emerging and selected metaphors from the workshop. Copyright free images from Unsplash by: Lance Aspecr (Bridge); Jilber Ebrahimi (Glass); Robina Weermeijer (heart); Omar Flores (Choir); Aziz Acharki (Parrot); Artem Beliaikin (Clothes); Dan Cristian Padure (paint); Amit Lahav (Gummy bears). 
their possible civic embeddedness, exploring how we can bypass the idea of robots as fully autonomous and efficient agents with whom humans should negotiate roles. The authors propose consideration of communitydriven values and other interaction nuances as a way to design robots that may engage in codependent relationships with humans. Citizenship, in this piece, is viewed not in terms of legal rights and responsibilities but as a metaphor that could facilitate addressing the sociorelational implications of HRI in public spaces.

Using metaphors to break assumptions about robots, then, is not novel. Yet, it often manifests as an implicit practice that remains understandable and applicable only by the few who already have a rich knowledge and proficiency in design practices. Thereafter, in this work, we present a design exploration of metaphors whose method could potentially be adopted by the wider community of HRI researchers to reach new frontiers for social robots.

\section{A DESIGN EXPLORATION OF METAPHORS FOR HUMAN-ROBOT INTERACTION}

We explored the values and interaction possibilities that robots can bring to our lives by using metaphors as a generative tool to break free of traditional assumptions and elicit imaginative and novel ideas. To this end, we organized an online Workshop at the International Conference of Social Robotics ${ }^{1}$ called "Metaphors for Human-Robot Interaction" ${ }^{2}$. Participants in this workshop included 28 scholars and artists with varied backgrounds and interests, including filmmaking, philosophy, design, computer science, human-computer interaction, fashion, architecture, mechanical engineering, psychology, and fine arts.

${ }^{1}$ International Conference on Social Robotics (ICSR) website: https://sites.psu.edu/icsr2020/

${ }^{2}$ Workshop website: https://robotmetaphors.com/

${ }^{3}$ Link for the New Metaphors Toolkit Randomizer built for this work: https://www.michalluria.com/metaphors/

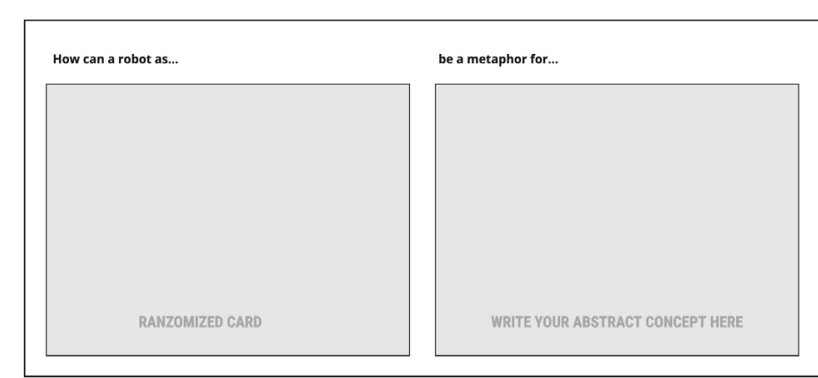

Fig 4. Sample card from the New Metaphors Toolkit [36]

To generate HRI metaphors, we used the New Metaphors Toolkit, a card-based design method that leverages juxtaposition to enable the emergence of hard-to-visualize phenomena [36]. This Toolkit, usually used in-person, consists of 150 cards in total, including 75 Thing 1 cards and 75 Thing 2 cards that can be combined to produce thousands of possible combinations. Thing 1 cards are purely textual and contain one word that can describe a phenomena, e.g., the word: "confidence." Thing 2 cards contain an image, generally a photograph, which can be combined with Thing 1 cards to form a metaphor, e.g., an image of a bird. While the New Metaphors Toolkit has been used to generate new ideas about visualizing sleep patterns [37], and in other contexts, it had not been previously applied to HRI or seen as a method to break free of assumptions about robots.

We adapted the New Metaphors Toolkit to an online setting and generated an online version of the cards with a randomizer to ensure the cards were drawn in random order and not according to participants' preferences. ${ }^{3}$

This enabled ideas that initially seemed unlikely to work together to generate original metaphors [3]. Additionally, we adapted the cards to a robot scenario. Figures 4 and 5 show an example card.

\section{${ }^{4}$ Miro board link: https://miro.com}

${ }^{5}$ Zoom link: https://zoom.us/

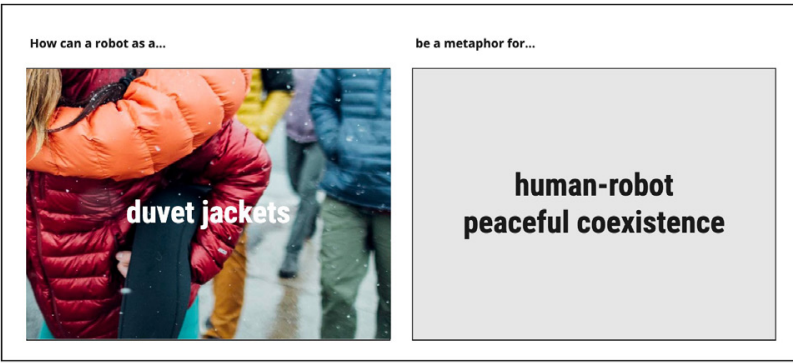

Fig 5. A sample card from the New Metaphors Toolkit adapted as example for our exploration of metaphors for HRI.

Our design exploration consisted of three activities that took about four hours to complete, using a Miro board ${ }^{4}$ an online collaborative whiteboard platform, and Zoom ${ }^{5}$ breakout rooms.

Activity 1. Participants individually used the metaphor randomizer to generate as many metaphors for HRI as they could. Participants clicked the randomizer button to find a card that would inspire the creation of an HRI metaphor. If the current generated card did not inspire the generation of a metaphor, they could click in the ranzomizer button which would generate a new card for a maximum of three consecutive times. From the generated cards, they picked the most inspiring one and generated a metaphor. This process was repeated and lasted a total of 13 minutes. We aimed at eliciting wild ideas for the metaphors, valuing a fast-paced activity. The goal was to achieve a high amount of metaphors for HRI with few time to judge or evaluate their value and feasibility. In total, participants were able to generate 21 original metaphors.

Activity 2. Participants individually generated metaphors for the concepts created by others. This resulted in different HRI metaphors using the same toolkit card, e.g., Figure 5 shows the generated metaphor "How can a robot as a duvet jacket be a metaphor for a protected human-robot relationship?". Participants had 15 minutes for this activity and generated a total of 31 metaphors. 
Activity 3. Participants, working in groups, picked one metaphor and created a detailed storyboard around it. This activity combined brainstorming and collective mapping to unpack the metaphors' qualities and create an abstraction of how they can be applied to HRI. Participants were distributed in 4 groups of 5-6 and worked in small groups. They started by unpacking their idea by discussing the charateristsics of the metaphor they were working on, and by reflecting on the concept of robot they wanted to promote. After this, they created a storyboard detailing how this metaphor for HRI would be applied to a real-world scenario in the context of education, home, assistive, and the workplace.

A total of 82 metaphors were generated (see Figure 3), which we evaluated and elaborated upon in the format of storyboards. We discussed the meaning of the metaphors and drew storyboards to showcase desirable real-world scenarios between humans and robots. We often tried to understand the deeper meaning of the metaphors by questioning concepts and visually illustrating them. The different sketches (see Figure 6) that lead to these storyboards support the visual imagination thinking process and helped make the abstract concept behind a metaphor more concrete, real, conceivable, and desirable.

The generated metaphors and storyboards serve as the first main contribution of this work, showcasing how robots can be envisioned in new relations with humans. A secondary contribution of our work is to provide a comprehensive list of current assumptions about robots and use the generated metaphors as a way to break free from these assumptions.

\section{BREAKING FREE FROM ASSUMPTIONS IN HUMAN-}

\section{ROBOT INTERACTION}

The workshop yielded a broad range of speculations and perspectives about how robots might be different, but it was insufficient to reframe this design space as is. To apply all our generated ideation data, we used an Affinity Diagramming approach to identify and group ideas according to the assumption that they challenge. This was the best approach for our process given our starting point of abundant alternative robot ideas and our goal of using them to identify unknown assumptions and reframe the design of robots within the field.

We identified three categories of assumptions that were challenged in ideation: assumptions about robot physicality, assumptions about robot role, and assumptions about robot interactive behavior. While these categories are not novel and works in HRI already addressed ways to break free of them by proposing different ways of conceptualizing robots, this work provides a comprehensive list of all the assumptions (both from the workshop and from the literature), which help better define the problem space. In this section, we present specific assumptions that were challenged in each category, followed by a discussion of how we believe designers and researchers can use them to reframe their own work. For example, robot designers can use these assumptions to transform how they currently design robots, a process that is repetitive and dated, into a more daring, interesting, and joyful way of designing robots that will integrate our societies and interact with us. Despite being challenged by prior work, these assumptions persist in the minds and work of researchers, as shown in our workshop. Perhaps this is because no other work has explicitly defined the assumptions held for robots and how to subvert them, as we uniquely contribute in this paper (see Figure 11).

\section{Assumptions in robot physicality}

The first set of challenged assumptions address the robots' form and physicality-how the robots' morphology is designed and how their physicality relates to the surrounding.

Lifelikeness. When the word "robot" is used, people frequently imagine a human- or animal-like artifact. Ideas in our workshop challenged this perspective and suggested robots that look like a doorknob, a shadow, or as morphing patterns on a brick wall. Some work in the field suggests robots that are non-anthropomorphic [2],
[40] and that are not life-like, but rather take the form of moving tangible objects $[33,53,56]$.

Otherness. Some robots suggested in the workshop differed from most robots in that they were not imagined as separate entities, but rather as part of the human body. This suggests a more fluid design space between a robot and a human cyborg. Some ideas include a robot as an extension of the body (for example, a "third-arm" robot) [60], robots as wearables, a robot that is constantly attached to a human (like a parrot sitting on one's shoulder), and even a robot as a tumor.

Localness. Most robot designs suggest that a robot is within a single location [49], yet we find that a single robot can be in multiple places at once, for example, in the form of "stations" across space and time. Some work in this area discusses the ability of robots to re-embody and co-embody different physical devices and machines to interact with a person.

\section{Assumptions about robot role}

The next set of assumptions address a robot's role: what is its primary function and goal when interacting with individuals? Does it have to be "useful" as usually suggested in robot designs?

Efficiency. Robots are primarily thought of as machines. As a result, they are frequently designed as efficiency tools. Yet robots can serve in roles that we do not usually associate with machines. For example, a robot might reflect the status of a home, a person or a situation, or a robot could be a piece of clothing that is used for selfexpression.

Commodification. People most often consider robots as something one can purchase, like a smartphone or a computer. But our process suggests alternatives, such as robots as art, robots as part of the public sphere, and robots to support nature. This is in line with recent calls for taking a more-than human centered design perspective when shaping complex technologies like robots $[15,23]$. For example, imagining a robot as a guardian of nature (rather than the human), which clears 


\section{DIVERGING THROUGH METAPHORS: A VISUAL EXPLORATION}
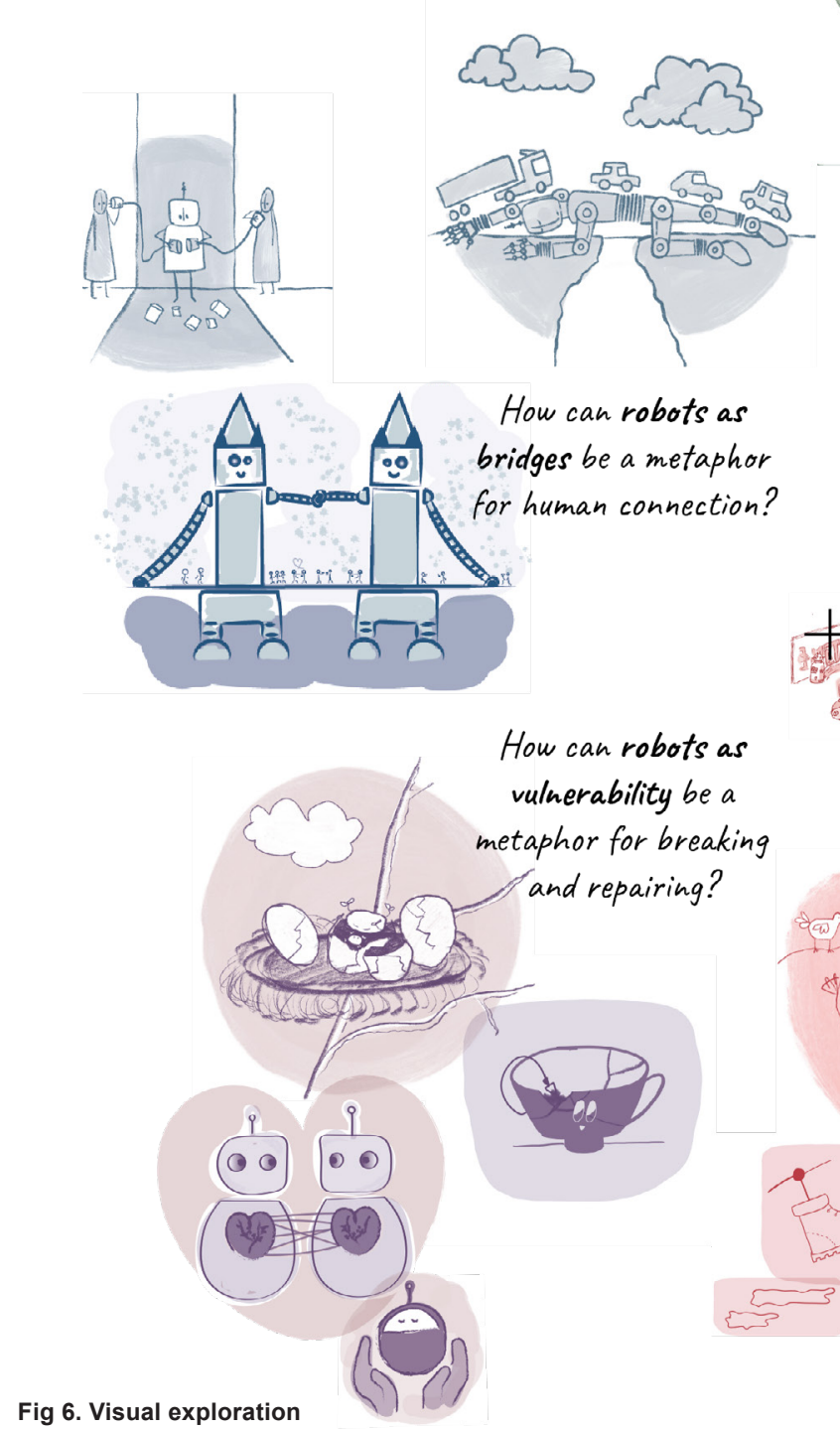

Fig 6. Visual exploration of selected metaphors.

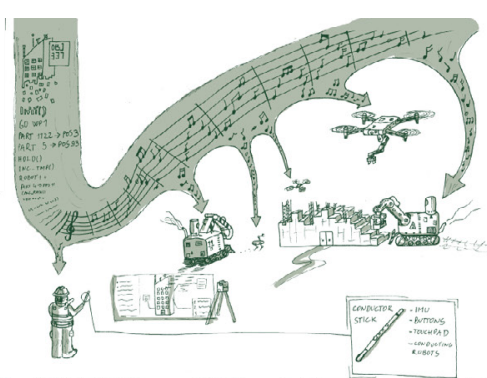

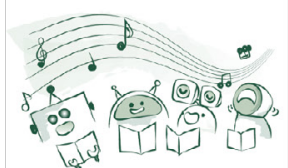

How can robots as a

choir can be a metaphor for the new art?

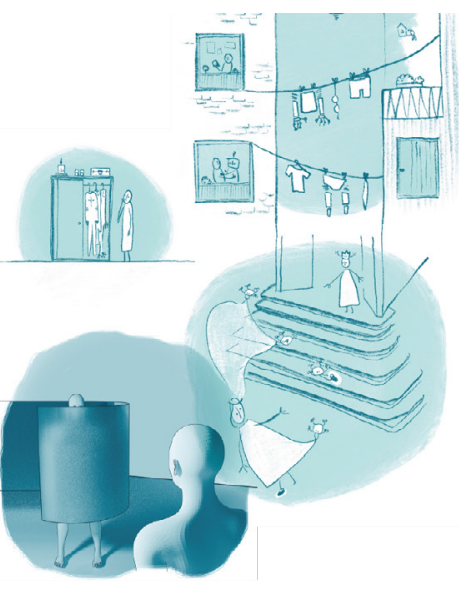

How can a robot as clothing be a metaphor for self-expression?

$$
\begin{aligned}
& \text { torstion } \\
& \text { [if } 1=01
\end{aligned}
$$

Pex

How can splashes of paint be a metaphor for deliberate actions of a disubedient robot?
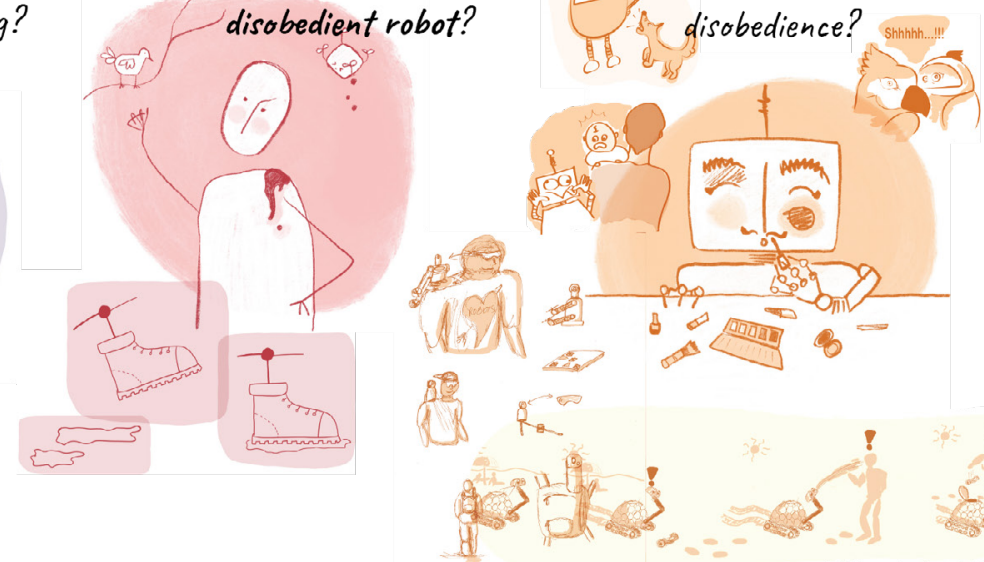

How can a tumor be a metaphor for the a robot that is part of you?

$$
\text { (o) }
$$

How can robot as sweetness be a

metaphor for addiction and pleasure?

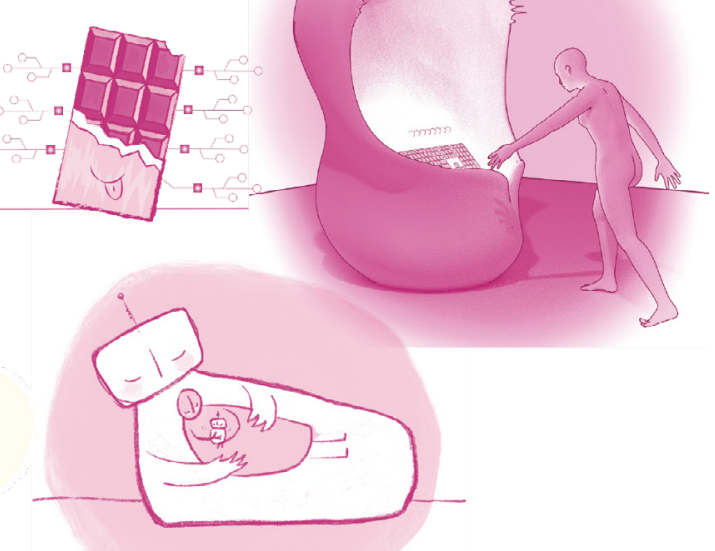




\section{APPLYING METAPHORS TO HUMAN-ROBOT}

\section{INTERACTION}

We further examined the use of metaphors in HRI by more deeply exploring how the metaphors could become feasible HRI scenarios. We used illustrated storyboards as a method [58] to visually represent how selected metaphors can inspire robot use in public spaces, the home, education, and assistive contexts.

\section{PERSONAL ROBOTICS}
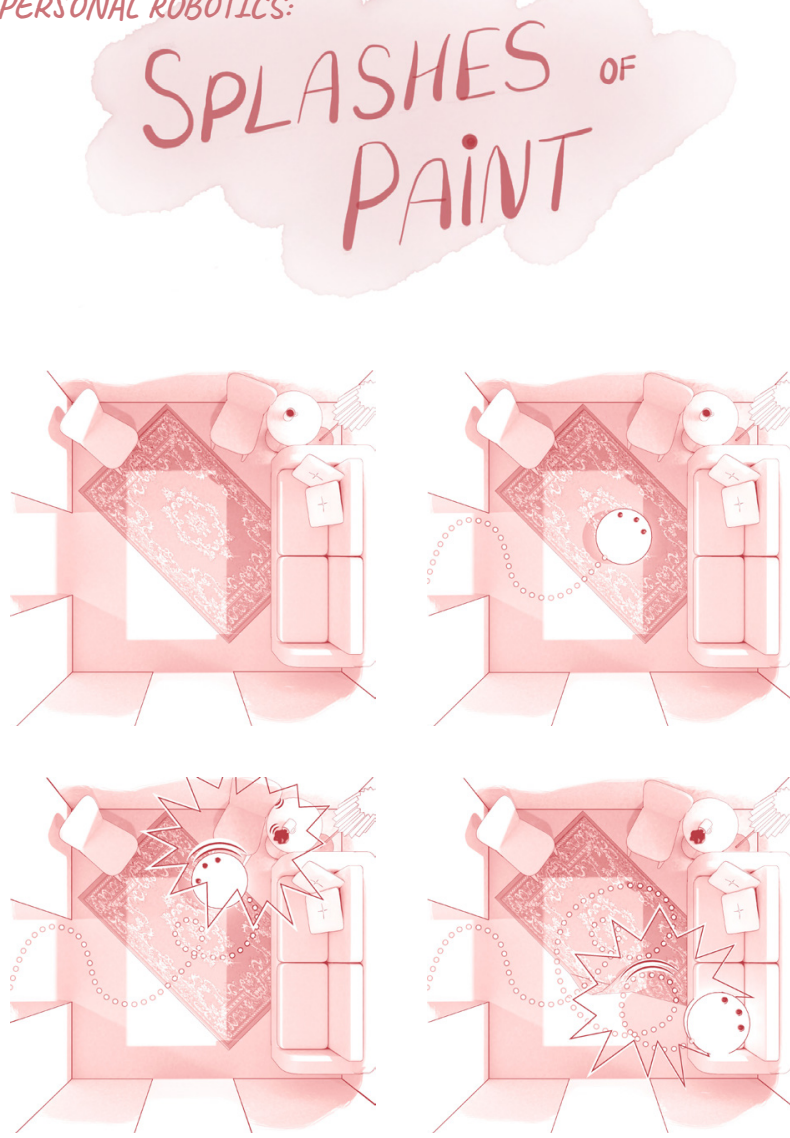

Fig 7. Storyboard about robot as splashes of paint in the context of personal robotics.
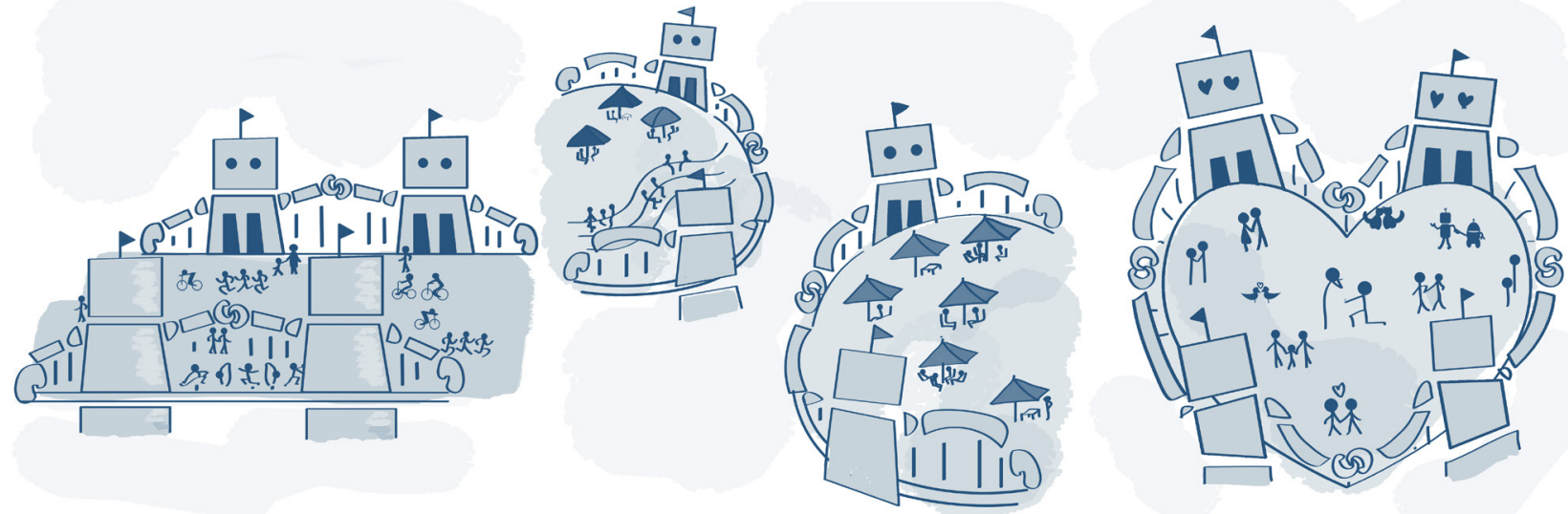

Fig 8. Storyboard about robots as bridges

in the context of community robotics.

Our home is our most personal, intimate, and safe space. We want to feel comfortable and at ease while at the same time feeling free to be creative and fully ourselves. We buy plants to promote this atmosphere or acquire pets to keep us company. In our work, we envision robots that help us break from routines or habits we want to change. However, instead of being polite and thoughtful, robots can be naughty and misbehave to promote change. In the storyboard, we see the round robot moving to the living room and bumping into the side table, spilling a mug of colfee. The robot continues to the couch, leaving splashes of paint on the floor and everywhere it goes. These colorful droplets of pain represent a given routine that the owner wants to change, such as decreasing the amount of working hours. The more hours the owner works, the more misbehaved the robot becomes, splashing the house and the walls with more and more paint. This signals the owner to stop working, take a break, and enjoy the day. By deliberately misbehaving, the robot can inspire fast routine changes. While this may seem irritating, when the owner looks around the house and sees colors everywhere, he is reminded of an artistic feeling that lives inside his own home.

\section{COMMUNITY ROBOTICS}

\section{BRIDGES}

Bridges are part of architectural landscapes and serve to connect two sides. In the context of our work, we envision robots as bridges, becoming part of the architecture of a city. By acquiring this form, robots can transform the flow of a city since their bridge-bodies are not static and can move. By moving, a robot influences where people meet and what they see and do. In the storyboard, a robot-bridge uses its arms to bound different spaces. In the first frame (left), the robot takes the form of a traditional bridge, letting people pass from one side to the other, connecting two different spatial points. In the second frame, the robot moves its arms to form a half-moon shape, creating areas of relaxation where robot forms a heart-shape and restricts people to being inside a space. This area evokes privacy and intimacy, eliciting emotions associated with marriage proposals but also with breakups. people can sit and enjoy a picnic. In the third frame, the 

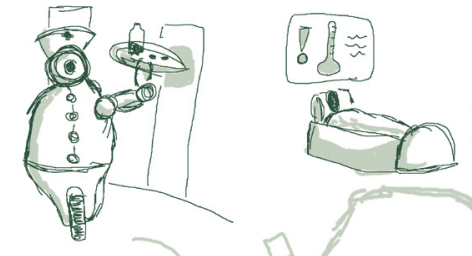

(a)

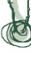

8100.80

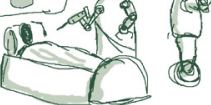

()

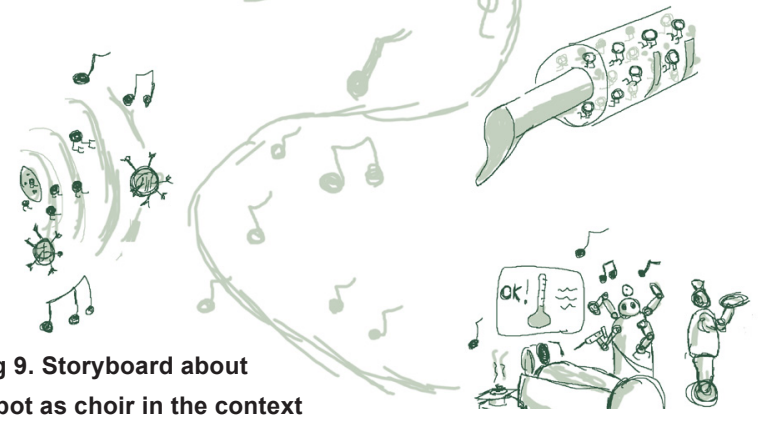

robot as choir in the contex

of assistive robotics.

\section{ASSISTIVE ROBOTICS: \\ A CHOIR}

Hospitals are emotional places that often feel cold and impersonal. In the context of our work, we envision robots as a choir in hospitals, representing a team of caregivers, each acquiring a different and essential role in patient care. By behaving as a coordinated and harmonious team, like a choir, robots can promote a sense of security and transparency for the patient. In the storyboard, we see a nurse-robot heading to the patient's room to provide food and perform essential checkups. The robot can communicate with the nanorobots that are part of the patient's bloodstream to provide accurate information about the patient's health needs. The nurse-robot administers a shot of vitamins to the patient without the need to wait for blood work results. The subsequent meals delivered to the patient by the smaller robot were cooked with ingredients that fasten the patients' recovery. These robots work together to form a musical composition for care, where the patient's well being is their only priority.
EDUCATIONAL ROBOTICS:

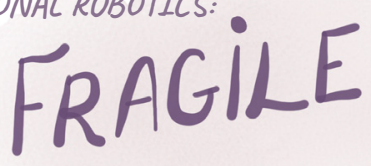

We protect children as they grow. Protecting and caring for someone implies the existence of important human abilities, such as empathy, responsibility, and perseverance. As children grow under our protection, they themselves acquire these qualities. In the context of our work, we envision robots as fragile that need care and protection. By being small, fragile, and in need of attention, the robot nurtures qualities of empathy and responsibility in the child.

Fig 10. Storyboard about robot as fragile in the context of educational robotics.
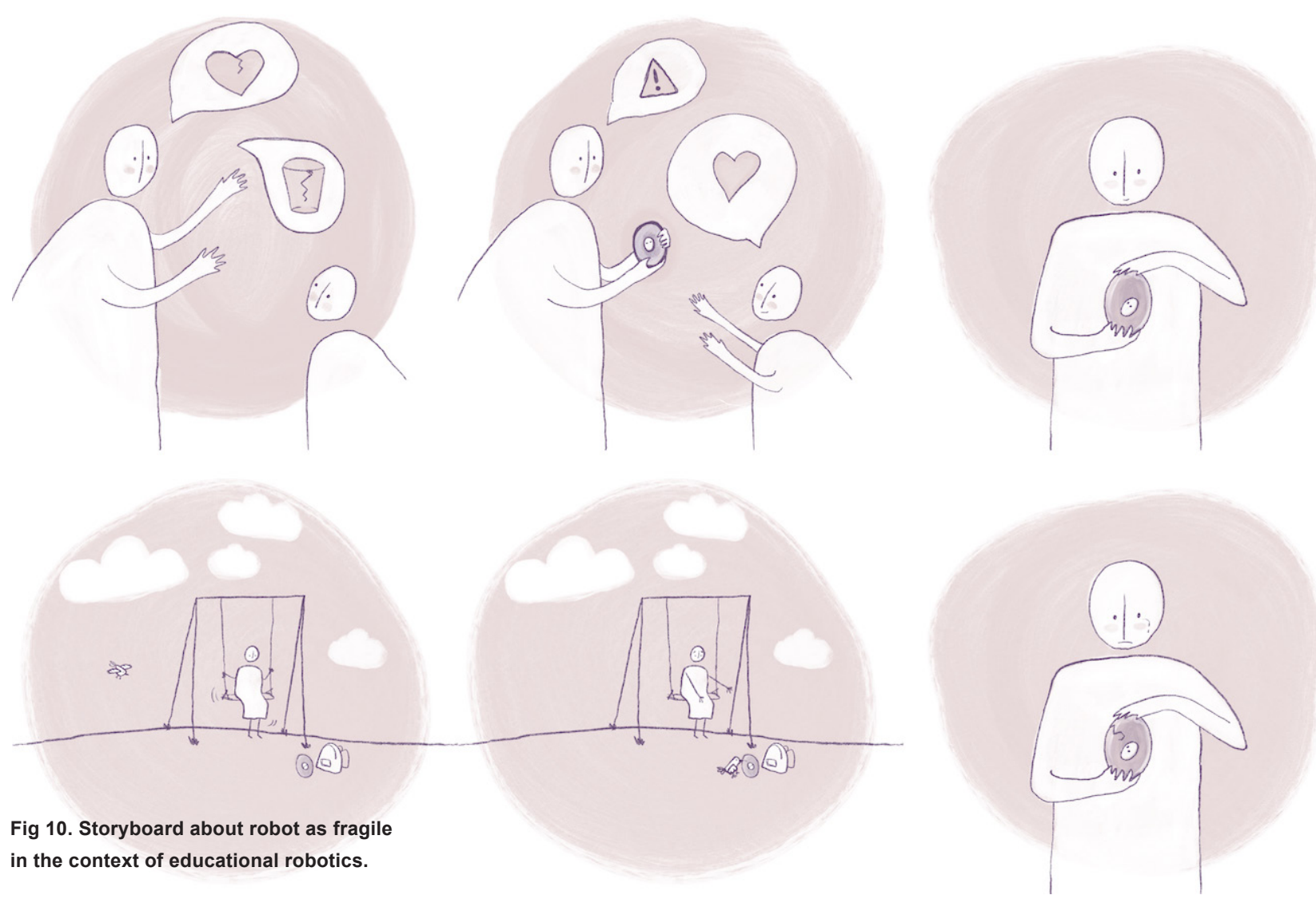

In the storyboards, we see a parent explaining to a child how the world can be dangerous and risky. But these are abstract concepts for a small child and hard to understand without having lived them. So a parent gifts the child a small robot and warns the child that much care for this robot is needed because it is fragile and can easily be hurt. The child goes to a nearby park and decides to play on a swing, leaving the robot farther away on the green grass. Interested by the egg-shaped robot, a bird approaches and starts pecking it. Given its fragility, the robot cracks, making the child sad. The child understands that more care is needed and goes back to the swing, this time carrying the robot on their lap, signaling protection and responsibility. 
the environment from human-made artifacts, could serve as guidance to shift design visions from only making humans more comfortable to designs that rest within planetary boundaries.

Flawlessness. Many of the ideas in our workshop countered the idea of a robot as an entity that is perfect at its job. Instead, much of the discussion was about robots that are imperfect, need assistance, or perhaps even have "undesirable" qualities that make them more relatable.

\section{Assumptions about robot interactive behavior}

The last set of assumptions challenge some of the interaction paradigms that are common for robots.

Positivity. Today, most agents and robots that we interact with are polite, positive and pleasant. In this workshop many alternatives were explored, including robots that are ill intentioned or that are rude, grumpy or forgetful. These are all opportunities to have alternative interactions with robots than what we are currently accustomed to.

Predictability. Most interactions with robots are also somewhat predictable, or at least strive to be so. But is that necessarily the best option? Some ideas suggested randomness and improvisation as key features, or even an inconsistent identity for robots by design.

Independence. Another assumption we identified suggests that robots are independent entities that work on their own and do not require any assistance unless they need human supervision [48]. Some generated ideas to counter this narrative include groups of robots that work as a collective, a dependent robot that needs help to complete its task, and a vulnerable robot that is primarily cared for.

Human-likeness. Much effort in robotics is spent to perfect human ways of interaction: computer-vision, natural language processing and haptics, among others. Non-human interaction channels are much less frequently explored in the field. In the workshop we examined the use of color, motion and sound effects as alternative channels of communication with robots.

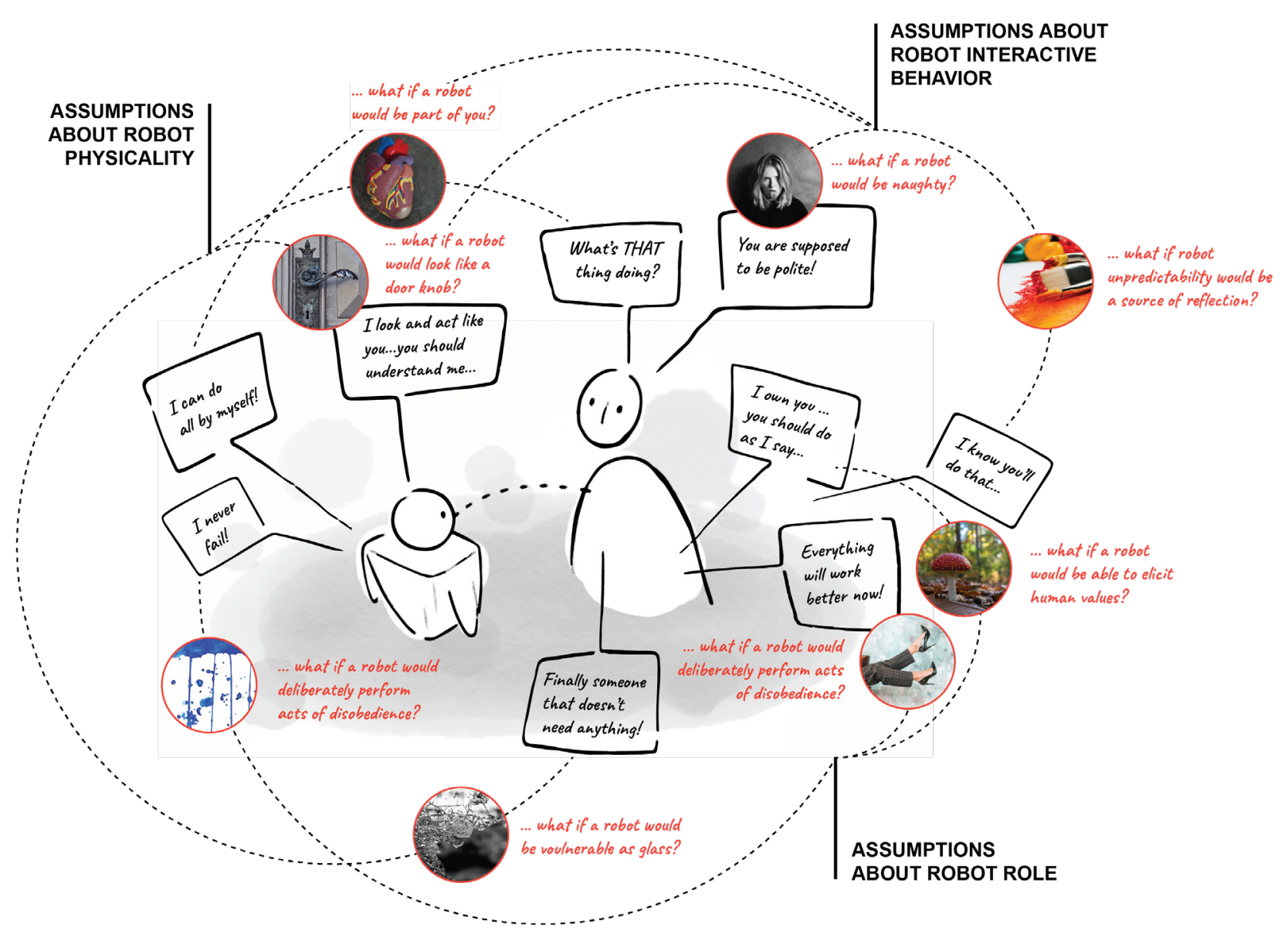

Fig 11. HRI assumptions and challenging metaphors.

\section{Reflecting on assumptions}

We view these groups of assumptions as tools to challenge future designs of robots and agents. While many of these assumptions have been overcome by researchers and designers, individuals new to this field are likely to join the fixated narrative of "robots." By reviewing a particular idea for a new robot through the different assumption-breaking lenses we propose here, researchers and designers can more promptly overcome the fixation stage of their work.
For example, consider a designer tasked with creating a robot to greet people in a store. The designer might use our list of assumptions to ask: Should this robot be humanlike, animal-like, or closer to an inanimate object? Does this robot need to be completely independent, or can it rely on other people and devices to complete its task? Is this robot a single entity that is located in a single place. or should it be more distributed? We believe that this list of assumptions can assist in countering the strong associations and narratives that are implied when using 
the word "robot" and allow the field to collectively, rather than anecdotally, broaden the contribution of robot design explorations far beyond what we can currently witness.

Building on what we have seen in previous work (e.g., [4]), we claim that design can answer - up to a large extent - to the growing demand for reflections and investigations on the impact and desirability of the robotic futures we propose. In Augers' words: design influences HRI by encouraging more 'focus on the complex reality of everyday life, the idiosyncrasies of people, the role of trends, status symbols, aesthetics, and more' [4]. As such, we believe that conducting these types of design explorations, aimed at challenging assumptions, would benefit the HRI field far beyond allowing divergent thinking when ideating about robots. They can rather help us speculate on what might be the potential consequences of the robots we design if contextualized and situated within existing social practices. Through counter-intuitive associations of ideas and 'para-functional' proposals, these types of design explorations can help the HRI field to develop a critical mindset towards its own practice.

As emerged from our investigation, exploring unconventional robot metaphors, such as robots that make mistakes or act unpredictably, lead us to profound considerations of social, cultural, and ethical implications of robotic artifacts. While we sought to provoke new ways to think about robots, the initial selection of metaphors, images, and the associations that participants made in the workshop were nevertheless rooted in particular worldviews and cultural and social perspectives and experiences. Even in seeking to promote more pluralistic approaches, the standpoints of the people and materials are still very much present in the resulting concepts. This too should be part of a reflective stance on the work.

\section{CONCLUSIONS AND FUTURE WORK}

In this work, we explored the use of metaphors as a tool to challenge existing assumptions in designing
HRI interactions as well as a framework to collectively explore novel ones. We surveyed prevailing assumptions about robots, which generally typecast them as flawless and subservient entities. To broaden the perspectives of robot roles, we challenged these assumptions by applying metaphors to frame robots against other concepts. We used the format of a workshop to explore metaphors as a creative method in HRI, gathering ideas that challenged underlying assumptions of robots, most notably regarding their physicality, roles, and interactive behaviors. The interaction design research community is well placed to offer creative reframing in the development of robots: designers' approaches, such as the method we have illustrated here, can provide a framework for roboticists. In particular, the New Metaphors method provides a framework for roboticists to break free from preconceived notions and broaden the design space of robots. We referenced outcomes generated throughout our workshop as initial inspiration.

Future work involves expanding on the themes emerging as a result of intentionally engaging in assumptionbreaking thinking in HRI interaction design. By deepening our understanding of the implicit and explicit dampening effects of these assumptions on the creative process, we can generate innovative priors that help both new and experienced HRI designers unlock novel design paradigms. This work can inspire roboticists, designers, artists, linguists, and engineers to develop robots that far surpass our current assumptions by acquiring different roles, shapes and forms, and interaction modalities with humans.

\section{ACKNOWLEDGMENTS}

We are grateful to all the participants from the "Metaphors in Human-Robot Interaction" workshop for their ideas and inspiration. We also show our gratitude to the reviewers for helping us improve the paper.

\section{REFERENCES}

[1] Ahmad, M. I., Mubin, O., \& Orlando, J. (2017). Adaptive social robot for sustaining social engagement during long-term children-robot interaction. International Journal of HumanComputer Interaction, 33(12), 943-962. DOI:10.1 080/10447318.2017.1300750

[2] Alves-Oliveira, P., Arriaga, P., Paiva, A., \& Hoffman, G. (2019). Guide to build YOLO, a creativity-stimulating robot for children. HardwareX, 6, e00074. DOI:10.1016/j.ohx.2019. $\mathrm{e} 00074$

[3] Arthur, K. (1964). The act of creation. London: Hutchinson, 751

[4] Auger, J. (2014). Living with robots: A speculative design approach. Journal of HumanRobot Interaction, 3(1), 20-42. DOI:10.5898/ JHRI.3.1.Auger

[5] Baraka, K., Alves-Oliveira, P., \& Ribeiro, T. (2020). An extended framework for characterizing social robots. In Human-Robot Interaction (pp. 21-64). Springer, Cham. DOI:10.1007/978-3-030-42307-0 2

[6] Bartneck, C., Belpaeme, T., Eyssel, F., Kanda, T., Keijsers, M., \& Šabanović, S. (2020). Humanrobot interaction: An introduction. Cambridge University Press. DOI:10.1017/9781108676649

[7] Boer, L., \& Bewley, H. (2018, June).

Reconfiguring the Appearance and Expression of Social Robots by Acknowledging their Otherness In Conference on Designing Interactive Systems (pp. 667-677). DOI:10.1145/3196709.3196743

[8] Bradshaw, J. M., Hoffman, R. R., Woods, D. D., \& Johnson, M. (2013). The seven deadly myths of" autonomous systems". IEEE Intelligent Systems, 28(3), 54-61. DOI:10.1109/ MIS.2013.70

[9] Casakin, H. (2004). Metaphors in the design studio: Implications for education. In DS 
33: Proceedings of E\&PDE 2004, the 7th International Conference on Engineering and Product Design Education, Delft, the Netherlands, 02.-03.09. 2004 (pp. 265-273).

[10] Casakin, H. P. (2006). Assessing the use of metaphors in the design process. Environmen and Planning B: Planning and Design, 33(2), 253-268. DOI:10.1068/b3196

[11] Casakin, H. P. (2007). Metaphors in design problem solving: implications for creativity. International journal of design, 1(2).

[12] Cheon, E., \& Su, N. M. (2018, February). Futuristic autobiographies: Weaving participant narratives to elicit values around robots. In Proceedings of the 2018 ACM/IEEE International Conference on Human-Robot Interaction (pp. 388-397). DOI:10.1145/3171221.3171244

[13] Cila, N., Hekkert, P., \& Visch, V. (2014). Source selection in product metaphor generation: The effects of salience and relatedness. International Journal of Design, 8(1).

[14] Coyne, R. (1995). Designing information technology in the postmodern age: From method to metaphor. Mit Press.

[15] Coulton, P., \& Lindley, J. G. (2019). More-than human centred design: Considering other things. The Design Journal, 22(4), 463-481.

[16] Crilly, N. (2015). Fixation and creativity in concept development: The attitudes and practices of expert designers. Design studies, 38, 54-91. DOI:10.1016/j.destud.2015.01.002

[17] Dorst, K. (2011). The core of 'design thinking' and its application. Design studies, 32(6), 521532. DOI:10.1016/j.destud.2011.07.006

[18] Dunne, A. (2008). Hertzian tales: Electronic products, aesthetic experience, and critical design. MIT press.

[19] Fernaeus, Y., Ljungblad, S., Jacobsson, M., \& Taylor, A. (2009, March). Where third wave HCI meets HRI: report from a workshop on user-centred design of robots. In 2009 4th ACM/ IEEE International Conference on HumanRobot Interaction (HRI) (pp. 293-294). IEEE. DOI:10.1145/1514095.1514182

[20] Dragan, A. D., Lee, K. C., \& Srinivasa, S. S. (2013, March). Legibility and predictability of robot motion. In 2013 8th ACM/IEEE International Conference on Human-Robot Interaction (HRI) (pp. 301-308). IEEE. DOI:10.1109/HRI.2013.6483603

[21] Dunne, A., \& Raby, F. Technological dreams series: No. 1. Robots (2007).

[22] Eglash, R. (2007). Broken metaphor: The masterslave analogy in technical literature. Technology and culture, 48(2), 360-369. DOI:10.1353/ tech.2007.0066

[23] Giaccardi, E., \& Redström, J. (2020). Technology and more-than-human design. Design Issues, 36(4), 33-44.

[24] Goodrich, M. A., \& Schultz, A. C. (2008) Human-robot interaction: a survey. Now Publishers Inc.

[25] Hassenzahl, M., Borchers, J., Boll, S., Pütten, A. R. V. D., \& Wulf, V. (2020). Otherware: How to best interact with autonomous systems. Interactions, 28(1), 54-57. DOI:10.1145/3436942

[26] Hekkert, P., \& Cila, N. (2015). Handle with care! Why and how designers make use of product metaphors. Design Studies, 40, 196-217. DOI:10.1016/j.destud.2015.06.007

[27] Hey, J. H., \& Agogino, A. M. (2007, January). Metaphors in conceptual design. In International
Design Engineering Technical Conferences and Computers and Information in Engineering Conference (Vol. 48043, pp. 125-134). DOI:10.1115/DETC2007-34874

[28] Hey, J., Linsey, J., Agogino, A. M., \& Wood, K L. (2008). Analogies and metaphors in creative design. International Journal of Engineering Education, 24(2), 283.

[29] Hurtienne, J., Löffler, D., Hüsch, C., Reihardt, D., Tscharn, R., \& Huber, S. (2020). Happy is up, sad is down -65 metaphors for design. BIS Publishers.

[30] Jansson, D. G., \& Smith, S. M. (1991). Design fixation. Design studies, 12(1), 3-11. DOI:10.1016/0142-694X(91)90003-F

[31] Jain, S., Thiagarajan, B., Shi, Z., Clabaugh, C., \& Matarić, M. J. (2020). Modeling engagement in long-term, in-home socially assistive robot interventions for children with autism spectrum disorders. Science Robotics, 5(39). DOI:10.1126/ scirobotics.aaz3791

[32] Jung, H., Wiltse, H., Wiberg, M., \& Stolterman, E. (2017). Metaphors, materialities, and affordances: Hybrid morphologies in the design of interactive artifacts. Design Studies, 53, 24-46. DOI:10.1016/j.destud.2017.06.004

[33] Knight, H., Lee, J. K., \& Ma, H. (2008, August). Chair Alarm for patient fall prevention based on Gesture Recognition and Interactivity. In 2008 30th Annual International Conference of the IEEE Engineering in Medicine and Biology Society (pp. 3698-3701). IEEE. DOI:10.1109/ IEMBS.2008.4650012

[34] Kwon, M., Huang, S. H., \& Dragan, A. D. (2018, February). Expressing robot incapability. In Proceedings of the 2018 ACM/IEEE International Conference on Human-Robot Interaction (pp. 87- 


\section{5). DOI: $10.1145 / 3171221.3171276$}

[35] Lakoff, G., \& Johnson, M. (2008). Metaphors we live by. University of Chicago press.

[36] Lockton, D., Singh, D., Sabnis, S., Chou, M., Foley, S., \& Pantoja, A. (2019). New metaphors: A workshop method for generating ideas and reframing problems in design and beyond. In Proceedings of the 2019 on Creativity and Cognition (pp. 319-332). DOI: $10.1145 / 3325480.3326570$

[37] Lockton, D., Zea-Wolfson, T., Chou, J., Song, Y., Ryan, E., \& Walsh, C. J. (2020, July). Sleep Ecologies: Tools for Snoozy Autoethnography. In Proceedings of the 2020 ACM Designing Interactive Systems Conference (pp. 1579-1591). DOI: $10.1145 / 3357236.3395482$

[38] Löffler, D., Dörrenbächer, J., Welge, J., \& Hassenzahl, M. (2020, April). Hybridity as Design Strategy for Service Robots to Become Domestic Products. In Extended Abstracts of the 2020 CHI Conference on Human Factors in Computing Systems (pp. 1-8).

[39] Löffler, D., Schmidt, N., \& Tscharn, R. (2018, February). Multimodal expression of artificial emotion in social robots using color, motion and sound. In Proceedings of the 2018 ACM/IEEE International Conference on Human-Robot Interaction (pp. 334-343). DOI: $10.1145 / 3171221.3171261$

[40] Lupetti, M. L. (2017). Shybo. An open-source low-anthropomorphic robot for children. HardwareX, 2, 50-60. DOI:10.1016/j. ohx.2017.08.003

[41] Lupetti, M. L., Bendor, R., \& Giaccardi, E. (2019). Robot citizenship: A design perspective. Design and Semantics of Form and Movement, 87.
[42] Luria, M., Sheriff, O., Boo, M., Forlizzi, J., \& Zoran, A. (2020). Destruction, Catharsis, and Emotional Release in Human-Robot Interaction. ACM Transactions on Human-Robot Interaction (THRI), 9(4), 1-19. DOI:10.1145/3385007

[43] Merriam-Webster.com. Merriam-Webster, 2011. Web. 10 January 2021.

[44] Moreno, D. P., Blessing, L. T., Yang, M. C., Hernández, A. A., \& Wood, K. L. (2016). Overcoming design fixation: Design by analogy studies and nonintuitive findings. AI EDAM, 30(2), 185-199. DOI:10.1017/ S0890060416000068

[45] Mirnig, N., Stollnberger, G., Miksch, M., Stadler, S., Giuliani, M., \& Tscheligi, M. (2017). To err is robot: How humans assess and act toward an erroneous social robot. Frontiers in Robotics and AI, 4, 21. DOI:10.3389/frobt.2017.00021

[46] Oates, M., Ahmadullah, Y., Marsh, A., Swoopes, C., Zhang, S., Balebako, R., \& Cranor, L.

F. (2018). Turtles, locks, and bathrooms: Understanding mental models of privacy through illustration. Proceedings on Privacy Enhancing Technologies, 2018(4), 5-32. DOI:10.1515/ popets-2018-0029

[47] Robinette, P., Li, W., Allen, R., Howard, A. M., \& Wagner, A. R. (2016, March). Overtrust of robots in emergency evacuation scenarios. In 2016 11th ACM/IEEE International Conference on HumanRobot Interaction (HRI) (pp. 101-108). IEEE. DOI:10.1109/HRI.2016.7451740

[48] Rosenthal, S., Biswas, J., \& Veloso, M. M. (2010, May). An effective personal mobile robot agent through symbiotic human-robot interaction. In AAMAS (Vol. 10, pp. 915-922)

[49] Santos, M., \& Egerstedt, M. (2020). From motions to emotions: Can the fundamental emotions be expressed in a robot swarm? International Journal of Social Robotics, 1-14. DOI:10.1007/s12369-020-00665-6

[50] Šabanović, S. (2010). Robots in society, society in robots. International Journal of Social Robotics, 2(4), 439-450. DOI:10.1007/s12369010-0066-7

[51] Sarrica, M., Brondi, S., \& Fortunati, L. (2019). How many facets does a "social robot" have? A review of scientific and popular definitions online. Information Technology \& People. DOI:10.1108/ITP-04-2018-0203

[52] Schon, D. A. (2001). Displacement of concepts. Psychology Press.

[53] Sirkin, D., Mok, B., Yang, S., \& Ju, W. (2016, February). Oh, I love trash: Personality of a robotic trash barrel. In Proceedings of the 19th ACM Conference on Computer Supported Cooperative Work and Social Computing Companion (pp. 102-105). DOI:10.1145/2818052.2874336

[54] Smith, S. M., \& Linsey, J. (2011). A threepronged approach for overcoming design fixation. The Journal of Creative Behavior, 45(2), 83-91. DOI:10.1002/j.2162-6057.2011.tb01087.x

[55] Snodgrass, A., \& Coyne, R. (1992). Models, metaphors and the hermeneutics of designing. Design issues, 9(1), 56-74. DOI:10.2307/1511599

[56] Spadafora, M., Chahuneau, V., Martelaro, N., Sirkin, D., \& Ju, W. (2016, February). Designing the behavior of interactive objects. In Proceedings of the TEI'16: Tenth International Conference on Tangible, Embedded, and Embodied Interaction (pp. 70-77). DOI: $10.1145 / 2839462.2839502$

[57] Steinfeld, A., Fong, T., Kaber, D., Lewis, M., 
Scholtz, J., Schultz, A., \& Goodrich, M. (2006, March). Common metrics for human-robot interaction. In Proceedings of the 1st ACM SIGCHI/SIGART conference on Human-robot interaction (pp. 33-40).

[58] Truong, K. N., Hayes, G. R., \& Abowd, G. D. (2006, June). Storyboarding: an empirical determination of best practices and effective guidelines. In Proceedings of the 6th conference on Designing Interactive systems (pp. 12-21). DOI:10.1145/1142405.1142410

[59] Vasconcelos, L. A., \& Crilly, N. (2016). Inspiration and fixation: Questions, methods, findings, and challenges. Design Studies, 42,
1-32. DOI:10.1016/j.destud.2015.11.001

[60] Vatsal, V., \& Hoffman, G. (2018, May). Design and analysis of a wearable robotic forearm. In 2018 IEEE International Conference on Robotics and Automation (ICRA) (pp. 5489-5496). IEEE. DOI:10.1109/ICRA.2018.8461212

[61] Viswanathan, V. K., \& Linsey, J. S. (2013). Design fixation and its mitigation: a study on the role of expertise. Journal of Mechanical Design, 135(5). DOI:10.1115/1.4024123

[62] Weiss, A., Bernhaupt, R., Lankes, M. and Tscheligi, M., 2009, April. The USUS evaluation framework for human-robot interaction. In
AISB2009: proceedings of the symposium on new frontiers in human-robot interaction (Vol. 4, No. 1, pp. 11-26).

[63] https://www.freshconsulting.com/wp-content/ uploads/2020/06/Why-Robotics-Fail_FreshConsulting.pdf. Why Robotics Companies Fail. Web. 10 February 2021.

[64] Youmans, R. J. (2011). The effects of physical prototyping and group work on the reduction of design fixation. Design studies, 32(2), 115-138. DOI:10.1016/j.destud.2010.08.001 